\title{
Research on Library Information Resource Sharing Model Based on Resource Sharing
}

\author{
Yuanfeng Tang \\ Xiangsihu College of Guangxi University for Nationalities, Nanning, Guangxi, 530008, China \\ 1131738887@qq.com
}

Keywords: Resource Sharing, Library, Information Resources, Resource Sharing.

\begin{abstract}
With the rapid development of information technology, it promotes the good development of library information resource sharing, and promotes the transformation and promotion of library service. Based on this, this paper briefly expounds the current situation of library information resource sharing, and analyzes the mode of library information resource sharing based on resource sharing from the aspects of expanding the scope of information resource sharing, deepening the level of information service and realizing the mutual integration of market economy and public welfare respectively.
\end{abstract}

\section{The Current Situation of Library Information Resource Sharing}

With the continuous development of modern information technology, under the background of the interconnection of all things, information resource sharing has gradually become a new trend of library development. More and more scholars have explored the mode of information resource sharing in libraries.

Literally, information resource sharing refers to the establishment of a cooperative and coordinated relationship between different libraries and between libraries and other relevant institutions on the basis of the principles of equality, reciprocity and resources, the integration of various technical means and paths, the joint creation of shared information resources, and the best efforts to meet all the information needs of users. The development of information resource sharing has gone through many stages, first of all, library resource sharing, then document resource sharing, then information resource sharing. At present, whether it is the entity sharing of literature, the resource sharing of bibliography, the coordinated sharing of resources or the business of library and the sharing of management resources, etc. For example, since 2005, the Suzhou Library has gradually achieved unified procurement, cataloguing, distribution and loan repayment. Up to now, there are 126 general branches of the Suzhou Public Library, covering basically county-level and township-level libraries, and seven mobile service vehicles, with at least 60 trips per year. After the implementation of the general branch library model, the Suzhou Library (as shown in figure 1) has been optimized for both the resources and the library resources, which provides great convenience for the general users, and can experience the same service in the branch at the front of the home, and realize the interconnection and resource sharing of the library[1].

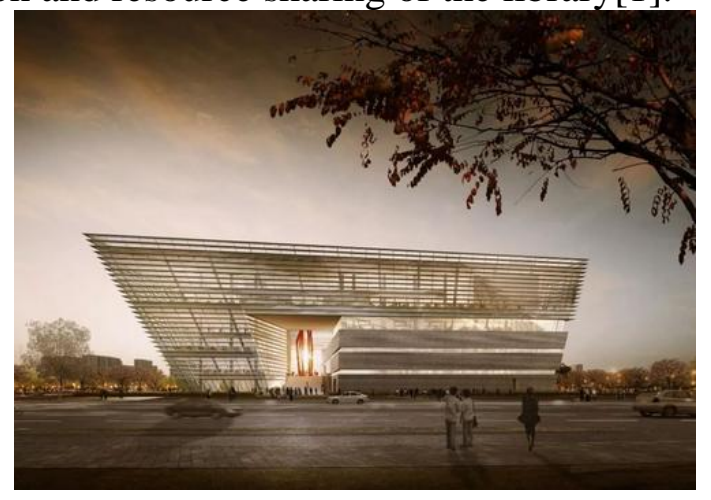

Figure 1 Suzhou second library 
Although there are many examples like the general library model in Suzhou, which promotes the good development of the library, there are still some shortcomings in the information resource sharing of the library nowadays, some problems need to be solved, for example, how to use the new technology to promote the continuous progress of the information resource sharing of the library, with the rapid development of the modern technology and the transformation of the digital library, the users have put forward some new demands on the resources of the library, put forward higher standards in the aspects of knowledge sharing, book borrowing and document transmission, and the application of the new technology in the information resource sharing of the library. Furthermore, it is necessary to solve the problem of unbalanced distribution of library information resources, which is influenced by the natural environment and economic environment, and there are certain differences in the development level of libraries in eastern, central and western China, especially in the western region, the development level of libraries is relatively backward, which affects the overall development level of national libraries and the rapid and steady development of libraries.

\section{Analysis of Library Information Resource Sharing Model Based on Resource Sharing}

Along with the great improvement of national economic level and the rapid development of information technology, the internal and external environment of the library has changed. Library information resource sharing belongs to a kind of information industry chain sharing, realizing bibliographic information and supply and demand information sharing in the middle and downstream units of library and information industry chain is helpful to promote the development of library information resource sharing better, and this sharing mode mainly has the following characteristics.

\subsection{The Sharing of Information Resources has Gradually Expanded}

In the past, most of the library information resources are concentrated between different libraries. With the continuous development of network technology, the boundaries between the production links, organizational links, storage links, development links, transmission links and services of information resources are more and more blurred. The information resource sharing of the library should be developed according to this law. The library not only needs to develop the document information resource for the second time, but also needs to be responsible for collecting all kinds of information resources, storing information resources, and developing these information resources to provide customers with corresponding information resources and so on[2].

The library needs to change for the whole society, first of all, it needs to break the shackles of the previous resource sharing mode, integrate the market mechanism into the information resource sharing link of the library, and organize the effective work of all kinds of information marketing. Secondly, the library can also strengthen the connection with the departments of each industry chain of academic information, and realize the co-existence of information resources. For example, in the best-selling stage of the book market, the reader's reading information collected by the library can be used by the publishing house and the competent department. In the electric interview section of the library, it can establish a tripartite cooperation with the data supplier and the bookseller to share a series of information materials such as bibliography. Finally, expand the scope of shared audience, libraries should expand the scope of existing readers, for example, in Wuhan University, more than 50 university librarians formed a consensus, signed the library information resources sharing Wuhan declaration, encourage other libraries to participate in the cooperation, figure 2 is the campus beauty of Wuhan University. At the same time, we also need to pay attention to the construction of grass-roots libraries, strengthen the information support to the rural areas or other areas of poor economic level, and do a good job of resource sharing in these areas, for example, the migrant workers' library set up in Beijing is a positive exploration. 


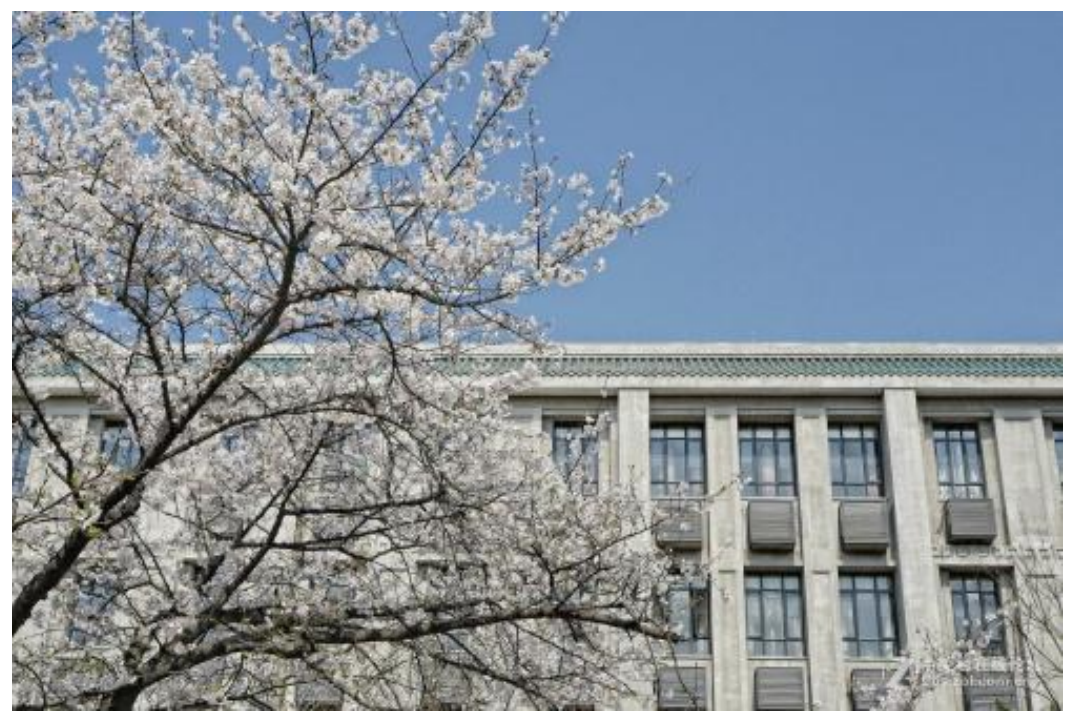

Figure 2 Campus view of Wuhan university

\subsection{Deepening Information Services}

Many years ago, libraries put forward declarations such as reader-first and service-centered. In the present situation, we should think about information services at the level of information resource sharing, advocate the universal service of the whole society, and truly realize everything for the purpose of readers. No matter any work of the library, it is necessary to take the reader's information needs and interests as the starting point to deepen the quality and quantity of information services, such as the establishment of information sharing area, which is referred to as IC, as shown in figure 3.

IC belongs to the extension of the electronic reading room of the library. It is the change made by the library to meet the challenge as the digital library evolves. By creating a new place in the existing library, the IC brings together librarians, researchers and scholars, classifying the collection resources according to the different disciplines, combining many traditional documents with the Internet, providing librarians with on-site consultation, software inquiry, network computing service, thesis writing teaching and so on. A series of library services, such as borrowing books, returning books, issuing certificates and transmitting the original texts, are available at the Information Sharing Office[3].

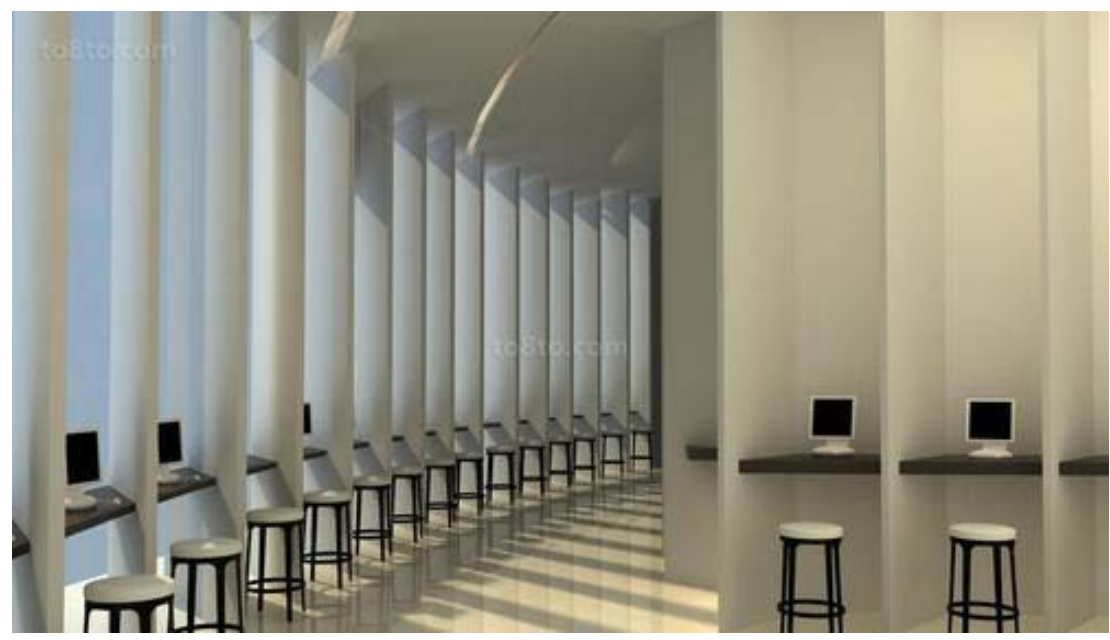

Figure 3 Library IC

The construction and application of the library information sharing office means the progress of the library information resources sharing, which can not only cooperate with the archives, children's palace, museum and other institutions or enterprises and government departments, but also expand the scope of library information sharing to the whole society. 


\subsection{Realizing the Integration of Market Economy and Public Welfare}

The library is a kind of cultural and educational institution, which has the characteristics of public welfare, so there are certain social benefits, non-competition, government behavior, unpaid and information resource sharing. By studying the history of library development, it is not difficult to find that on the one hand, the construction of library ensures and maintains the right and freedom of the audience to explore knowledge, and at the same time, through the sharing of information resources, the social benefit of library can reach the highest, which makes the library have the special characteristics of non-division, non-competitive and non-exclusive. In essence, the main purpose of building a library is to save money, to use centralized services to meet the information needs and knowledge needs of different groups, and then to promote the progress of human and society, and the information resource service is a hand in the sharing of library information resources. Most of the services provided by the library sharing system are free of charge. In this mode of free service, the responsibility and motivation of some member libraries are not enough, and the enthusiasm of information resources construction and sharing is not high, so the quality of information services provided is difficult to guarantee, and the units that are profitable are developing rapidly, such as Wanfang in Beijing, Weipu in Chongqing and Tsinghua Tongfang in Tsinghua University, and so on. Some scholars point out that while adhering to the principle of public welfare, the sharing of library information resources should pay attention to its own economic benefits, introduce the market economy into it, construct the output model of the library by means of economic means and the principle of statistics, and provide reference for the decisionmaking of the library by analyzing the flow of data to analyze the rules of input and output[4].

\section{Conclusion}

To sum up, under the background of resource sharing, users put forward higher service requirements to the library in the aspects of knowledge sharing, book borrowing and document transmission. Therefore, the library should actively create the mode of information resource sharing, strengthen the contact with the departments of each industry chain, expand the audience range, increase the technical support to the economically underdeveloped areas, continuously improve the service quality and service level of the library, and realize the sharing of information resources in a real sense.

\section{References}

[1] $\mathrm{Xu}$, Ling. Urban public library resources open sharing and service regionalization model. Industry and Technology Forum, vol. 19, no. 01, pp. 250-251, 2020.

[2] Chen, Shi. Information resource sharing approach analysis based on wisdom library. Media Forum, vol. 2, no. 24, pp. 144-145, 2019.

[3] Luo, Huanjun., Lei, Xin., he, Yuan. Regional library information resource sharing system construction analysis. Scientific Consulting (Educational Research), no. 12, pp. 58, 2019.

[4] Zhu, Cong. long. the construction and sharing mode of the characteristic collection resources of the university library. Heilongjiang Science, vol. 10, no. 21, pp. 72-73, 2019. 